\title{
Review
}

\section{Pain Management in Geriatric Burn Patients: A Scoping Review of Strategies and Key Issues}

\author{
Jonathan Bayuo
}

check for updates

Citation: Bayuo, J. Pain Management in Geriatric Burn Patients: A Scoping Review of Strategies and Key Issues. Eur. Burn J. 2021, 2, 184-193.

https://doi.org/10.3390/ebj2040014

Academic Editor: Naiem Moiemen

Received: 8 September 2021

Accepted: 12 October 2021

Published: 15 October 2021

Publisher's Note: MDPI stays neutral with regard to jurisdictional claims in published maps and institutional affiliations.

Copyright: (C) 2021 by the author. Licensee MDPI, Basel, Switzerland. This article is an open access article distributed under the terms and conditions of the Creative Commons Attribution (CC BY) license (https:// creativecommons.org/licenses/by/ $4.0 /)$.
School of Nursing, The Hong Kong Polytechnic University, 11 Yuk Choi Road, Hung Hom, Kowloon, Hong Kong; jonathan.bayuo@connect.polyu.hk

\begin{abstract}
The effect of poorly treated pain is well documented in the literature. To offer support for the development of geriatric-specific pain management protocols, this review sought to scope the literature to identify what has been accomplished in geriatric burn pain management and offer suggestions. Arksey and O'Malley's scoping review methodology was employed with extensive database and grey literature searches. A narrative synthesis was employed to analyse the evidence. The PRISMA extension guidelines for scoping reviews were followed in reporting this review. Sixteen evidence types comprising eleven reviews, two retrospective studies, two book chapters, and one practice guideline were retained in the review. The two retrospective studies emerged from the United States. The review findings suggest that though a plethora of generic pain assessment tools exist, they are yet to be validated in the older adult burn population. Pain management strategies involved the use of pharmacological agents (mainly opioids), but no outcome regarding pain relief was reported. Key issues identified include cautious use of opioids, oversedation concerns, and varied complexities associated with pain management. Though the literature remains largely unexplored, the complexities associated with geriatric burn pain management suggest a need for a multidisciplinary approach. More prospective studies are also needed to evaluate both pharmacological and non-pharmacological interventions in the geriatric burn population.
\end{abstract}

Keywords: burns; geriatrics; pain management

\section{Introduction}

The older adult population is one of the fastest-growing populations and at the same time, remains highly susceptible to burn injuries [1,2]. The increased susceptibility of older adults to burn injuries is related to varied factors such as diminishing physical strength, altered protective mechanisms, poor eyesight, presence of several pre-morbid conditions, and diminished reaction time [3]. The process of aging is associated with several physiological alterations that result in decreased functional reserves and a diminished ability to adapt to the injury. The relatively atrophic skin of elderly persons makes the resulting burns deeper [4,5]. The severity of the hypermetabolic response to burn injury increases with age and may result in an exaggerated response to the injury among elderly persons [5]. Clinical management of elderly persons with burns, therefore, remains a challenge with poor outcomes such as increasing morbidity levels/development of complications during acute hospitalisation and high mortality risk [5,6].

Among other therapeutic management strategies for burned patients, burn-related pain remains a major clinical problem due to its complex nature [7]. At least four forms of burn pain were identified in the existing literature: procedural, background, breakthrough [7] and post-operative pain [8,9], which may also be associated with distress and anxiety creating a need for a multimodal, multidisciplinary approach to burn pain management [7]. Additionally, the burn pain experience is uniquely individualistic and can even vary for the same person throughout the recovery trajectory [10]. Burn pain and its management may be particularly problematic for elderly burned patients considering potential underlying 
chronic pain, pre-existing co-morbidities, altered pharmacogenomic/pharmacological responses, and polypharmacy issues $[1,2,11]$. Experimental research has also observed the existence of reduced pain tolerance to stimuli among the elderly [12]. Additional barriers such as underreporting of pain and misconceptions among healthcare staff can also contribute to the suboptimal management of pain among elderly burned patients [13].

The effect of poorly treated burn-related pain is well documented in the literature. For instance, poorly managed post-burn pain can contribute to the development of chronic pain, paresthesia [14-17] and even worsen psychological issues and interfere with activities of daily living $[18,19]$. Moreover, the presence of burn-related pain has been correlated with suicidal ideations by the time of discharge from the burn unit [20]. The presence of acute pain can also provoke anxiety and reluctance among patients to participate in a therapeutic regimen which can translate into longer hospital stays [21]. For the elderly, poorly treated pain can increase the incidence of delirium [22]. In the long term, quality of life may be adversely affected [23].

Successful pain management involves pain assessment using validated, age and condition-specific tools, intervention, and evaluation by trained staff [24]. Though varied pharmacological and non-pharmacological strategies exist to manage burn-related pain [25,26], there are still reports of poorly treated pain [21]. For elderly burned patients, this may be worse considering the complexities associated with the injury, ageing process, and other underlying issues. Although burn pain management protocols exist, they may not necessarily reach the elderly burn population. The urgent need for geriatric-specific pain and anxiety management protocols was re-echoed recently [2], particularly as elderly persons are a high-risk group when it comes to burn injuries [1-3]. As a starting point, this review sought to scope the literature to identify what has been accomplished in geriatric burn pain management and offer suggestions for further studies.

\section{Materials and Methods}

\subsection{Review Design}

A scoping review approach was utilised for this study [27]. Scoping review focuses on mapping key concepts and identifying gaps in an area [28] which makes it appropriate for this review. Additionally, scoping review permits the inclusion of varied study types which makes it useful for the current review. The PRISMA Extension Guidelines for Scoping Reviews were followed in reporting this review [29].

\subsection{Information Sources and Search Strategy}

An initial limited search was carried out in PubMed and CINAHL with a set of preplanned search terms which were modified as the search proceeded and subsequently, informed the development of a detailed search strategy. The information sources/databases searched include EMBASE, CINAHL, PubMed, Cochrane Library and Web of Science. The reference lists of the potential papers were also hand-searched for potential papers. To fully scope, MedNar and Trove were searched for grey literature. The databases were searched from inception to March 2021. The search terms used to guide the process were: "burn injury" or "burns" or "burn trauma" or "burns" or "burn injury" or "burns trauma" or "major burns" AND "pain management" or "pain relief" or "pain control" or "pain reduction" or "managing pain" or "analgesia" AND "geriatrics" or "older adults" or "elderly" or "aged" or "older" or "elder" or "elderly" or "senior".

\subsection{Study Selection}

All studies from the database search were pooled to EndNote X9.2 following which duplicates were removed. Title and abstract screening were carried out to identify relevant studies. Full-text versions of the relevant studies were retrieved. The following inclusion criteria were applied: (1) studies reporting pain management among elderly persons with burns irrespective of the design (2) reported in English. Studies that included other age groups in addition to older burned patients were considered for inclusion if they presented 
data regarding pain management in the older burned patients. Preprints were however excluded. The study selection process was reported using a PRISMA flowchart (see Figure 1 below).
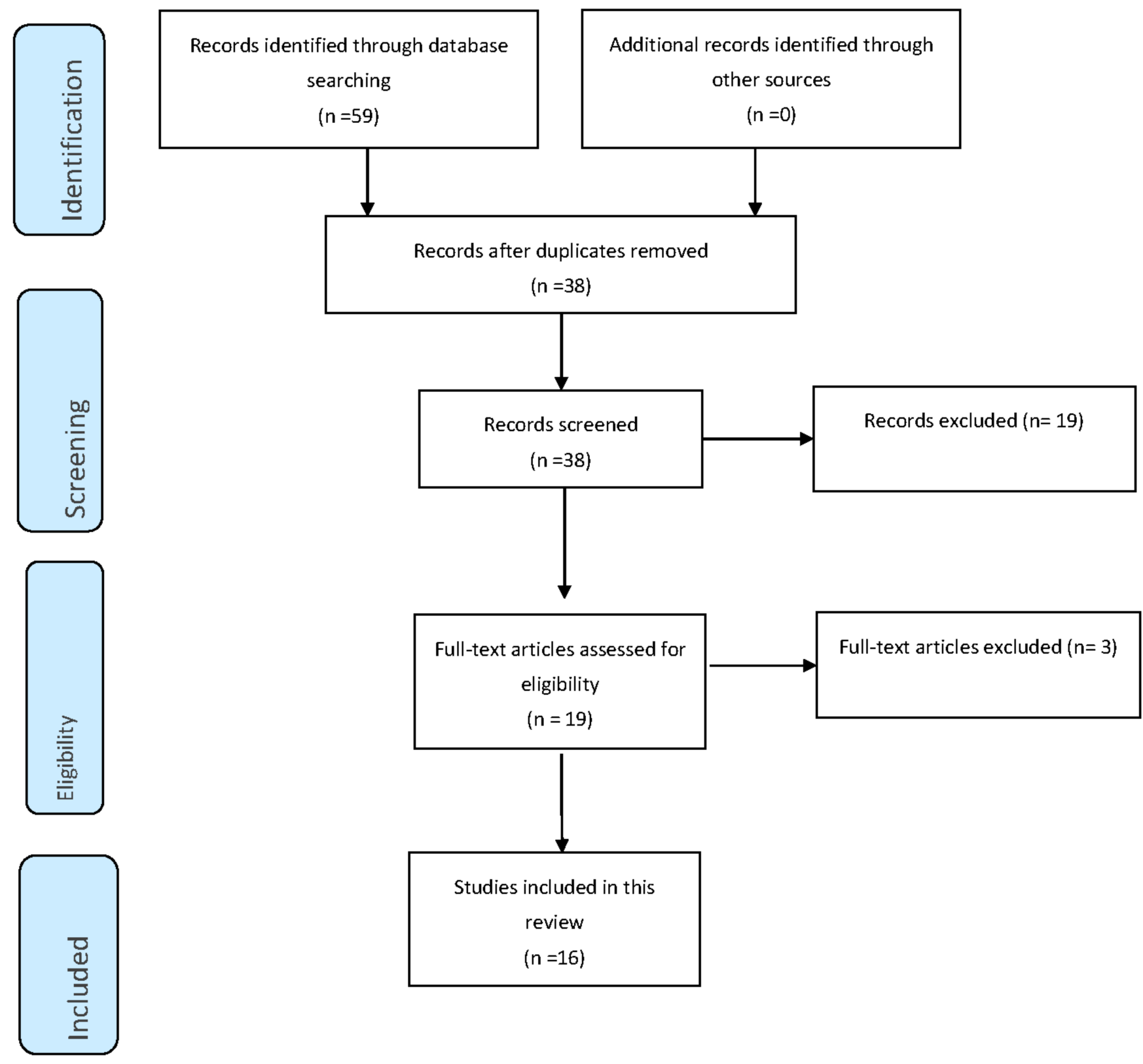

Figure 1. PRISMA Flowchart of Study Selection.

\subsection{Data Synthesis}

Standard information was obtained from each study into an MS Excel 2013 worksheet designed for this purpose (see Table 1). Details regarding pain and pain management of elderly burned patients reported across the studies were also transferred to the analytical grid. The author then examined these findings and formulated codes across the included studies. Similar codes were aggregated to develop concepts that formed the basis of undertaking a narrative synthesis (see Supplementary Table S1).

\section{Results}

\subsection{Study Characteristics}

Following the extensive search and screening, sixteen sources of evidence were retained in the review. This comprised of eleven reviews [7,19,30-38]; two retrospective 
studies [39,40]; two book chapters [41,42]; and one practice guideline [43]. The two retrospective studies emerged from the United States $[39,40]$. All the reviews and book chapters discussed burn management in the elderly broadly with few sections dedicated to pain management which may highlight the limited scope of work regarding geriatric burn pain management. A summary of the study characteristics is presented below in Table 1:

Table 1. Summary of included studies.

\begin{tabular}{|c|c|c|}
\hline Author(s)/Year/Setting & Evidence/Study Type & Aim and Methods \\
\hline Abu-Sittah et al. [32] & Review & $\begin{array}{l}\text { To evaluate risk factors, pathophysiological and immunological conditions that } \\
\text { affect response to burn injury in the elderly population. } \\
\text { Literature review }\end{array}$ \\
\hline Askay at al. [19] & Review & $\begin{array}{c}\text { To review the literature on the physiologic and psychologic effects of acute burn pain. } \\
\text { Literature review }\end{array}$ \\
\hline Connor-Ballard, [34] & Review & $\begin{array}{c}\text { To provide an in-depth discussion of pain management (topical medications and } \\
\text { the psychological aspects of burn pain) } \\
\text { Literature review }\end{array}$ \\
\hline Davidge and Fish, [30] & Review & $\begin{array}{c}\text { To review the specific issues that need to be considered when treating older adults } \\
\text { with burn injury. } \\
\text { Literature review }\end{array}$ \\
\hline Faucher et al. [43] & Practice guidelines & $\begin{array}{c}\text { To review principles of pain management and to present a reasonable approach to } \\
\text { the management of the complex pain associated with burn injurySystematic } \\
\text { literature review and expert opinion }\end{array}$ \\
\hline $\begin{array}{l}\text { Honari et al. [40] } \\
\text { USA }\end{array}$ & Retrospective study & $\begin{array}{c}\text { To assess the range of requirements and use of opioids among elderly patients } \\
\text { with burns of different age categories } \\
\text { Retrospective chart review }\end{array}$ \\
\hline Huang et al. [35] & Review & $\begin{array}{l}\text { To review the modern trend of management of elderly burn patients. } \\
\text { Literature review }\end{array}$ \\
\hline $\begin{array}{l}\text { Hutchison et al. [39] } \\
\text { USA }\end{array}$ & Retrospective study & $\begin{array}{l}\text { To retrospectively characterise pain management strategies (including opioids and } \\
\text { non-opioid adjuncts) in this patient population. } \\
\text { A retrospective cohort study of patients age }>65 \text { with burns }<20 \% \text { total body } \\
\text { surface area (TBSA). }\end{array}$ \\
\hline Keck et al. [31] & Review & $\begin{array}{c}\text { To give an overview of the current literature concerning specific considerations } \\
\text { concerning elderly burns. } \\
\text { Literature review }\end{array}$ \\
\hline Montgomery, [38] & Review & $\begin{array}{l}\text { To provide an overview of pain management in burn injury } \\
\text { Literature review }\end{array}$ \\
\hline Norman and Judkins [33] & Review & $\begin{array}{l}\text { To provide an overview of the management of pain in the patient with burns } \\
\text { Literature review }\end{array}$ \\
\hline Nosanov et al. [36] & Review & $\begin{array}{l}\text { To describe the characteristics of pain following burn injury, methods of assessment, } \\
\text { multimodal pharmacological treatment, and non-pharmacological adjuncts. } \\
\text { Literature review }\end{array}$ \\
\hline Pham [41] & Book chapter & $\begin{array}{l}\text { To present the injury epidemiology, pathophysiologic differences and acute } \\
\text { management challenges in older patients. }\end{array}$ \\
\hline Sheaffer [42] & Book chapter & $\begin{array}{l}\text { To review burn care considerations in general, with an emphasis on managing } \\
\text { comorbidity in the setting of elderly burn care }\end{array}$ \\
\hline Sheridan [37] & Review & $\begin{array}{c}\text { To delineate the unique aspects of care for young children and the elderly that } \\
\text { impact the treatment of burn injury followed by a discussion of the research } \\
\text { priorities for young children and the elderly. } \\
\text { Literature review and expert opinion }\end{array}$ \\
\hline Summer et al. [7] & Review & $\begin{array}{l}\text { To provide an overview of the types of pain associated with a burn injury, describe } \\
\text { how these different types of pain interfere with the phases of burn recovery, and } \\
\text { summarise pharmacologic pain management strategies across the continuum of } \\
\text { burn care. } \\
\text { Literature review }\end{array}$ \\
\hline
\end{tabular}

\subsection{Concepts}

Two concepts emerged from the data: (1) strategies employed in managing geriatric burn pain, and (2) Key issues in managing pain in geriatric burns. 


\subsubsection{Concept 1: Strategies Employed in Managing Geriatric Burn Pain} Pain Assessment

No burn-specific pain assessment tool was identified for the geriatric population across the included studies. Generic tools that were identified include visual analog scale (VAS), numeric rating scale (NRS), verbal description scales (VDS) and the McGill Pain Questionnaire [7,41]. One study suggested that the VDS is particularly suited for assessing pain in older adults, including those with mild to moderate cognitive impairment [7]. It was however observed in another study that observational scales may be more useful when the cognitive impairment or mechanical ventilation preclude self-reporting [41].

\section{Pharmacological Management of Pain}

All sources of evidence included in this review underscored the importance of exercising caution when using pharmacological agents to manage pain in the older burned patient considering potential adverse effects and underlying comorbidities. Generally, opioids [37,39,41,42] such as fentanyl [30,34,40], oxycodone [40], and hydromorphone [40] were mentioned to be titrated to the patient's needs and individual circumstances to manage procedural and breakthrough pain. In one paper, it was mentioned that the initial opioid dose for pain should be $25-50 \%$ of that in younger adults and titrated upwards to improve comfort [41]. More specifically, another review noted that fentanyl 25 micrograms administered intravenously over one to two minutes should be considered in incremental doses [34]. In one study, it was observed that elderly burned patients were discharged home with more opioids than utilised during their inpatient stay [39].

The use of acetaminophen as a non-opioid adjunct for managing pain in older burned patients was also reported [39] though another study cautioned that it might increase the risk of liver failure in older persons with preexisting liver diseases [31]. Subanesthetic doses of ketamine administered via intravenous or oral may be considered for procedures requiring deep sedation $[37,38]$. However, ketamine may lead to the emergence of delirious reactions, and it is recommended that it should be used concomitantly with midazolam [34,38]. Non-steroidal anti-inflammatory drugs (NSAIDs) and gabanoids were used less frequently [39] with one study noting that NSAIDs should be used with caution [33]. The use of meperidine was mentioned to be contraindicated in elderly burn patients with renal failure as its metabolites (normeperidine) may accumulate and cause seizures, confusion, and myoclonus [43]. Barbiturates, benzodiazepines, and tricyclic anti-depressants also require cautious use in older persons with reduced clearance [41].

\section{Monitoring}

Following administration of the pharmacological agents, it is necessary to monitor the elderly burned patient for both therapeutic and adverse effects. The simultaneous use of ketamine and midazolam may cause respiratory and cardiac suppression [38]. Thus, it was recommended that a Registered Nurse, certified and experienced in the safe intravenous administration of these medications should be present during their usage [34]. Additionally, other monitoring equipment (such as telemetry and pulse oximetry), anesthesia, oxygen, and respiratory therapy personnel need to be present in case of an adverse event [34]. Neurological exams may also be required prior to the use of opioids [42].

\subsubsection{Concept 2: Key Issues in Managing Pain in Geriatric Burns}

Varied issues were noted that require consideration in managing pain following burns in older persons. Older persons may have poor tolerance to opioids which may make it difficult to optimise pain control [30]. Additionally, the assumptions that pain perception decreases with age and chronic pain is a normal part of ageing can serve as barriers to attaining optimum pain control [32,41]. The need for cautious use of opioids and underlying comorbidities may also deter their use altogether leading to poor management of pain $[31,35]$. Healthcare providers' concerns regarding oversedation may also lead to undertreatment of pain [36]. Older adults with burns may also have difficulty in expressing 
pain which may adversely affect the pain management process [37]. The use of medications such as beta-blockers may also mask potential signs of pain [37]. Based on these complexities, it emerged that a multi-disciplinary approach to managing burn pain in older persons is warranted. This team should include pharmacists to aid in carefully titrating medications to reduce polypharmacy and geriatricians to support the comprehensive care of the older burned patient $[36,41]$.

\section{Discussion}

This review sought to scope the literature to map what has been accomplished in geriatric burn pain management. The review findings highlight that geriatric burn pain management remains largely unexplored creating critical gaps that warrant attention [2]. There is a general lack of pain assessment tools specific to the geriatric burn population and the generic types available which are often employed have not been validated among this group. This makes it difficult to draw conclusions regarding the overall utility of the generic scales in assessing pain in older burned patients. The review findings further note that opioids and acetaminophen are the most used pharmacological approaches to burn pain management. However, none of the included studies offered data regarding outcomes associated with these medications which makes it difficult to conclude their overall effect. Moreover, non-pharmacological approaches to burn pain management remains poorly evaluated among older persons with burns. Though the literature remains largely unexplored, the complexities associated with geriatric burn pain management suggest a need for a multidisciplinary approach including pharmacists and specialists from geriatric medicine to offer comprehensive support whilst considering underlying comorbid and polypharmacy issues. Overall, the evidence base regarding burn pain management in older burned patients is largely limited. The way forward is to develop geriatric-specific pain management protocols and evaluate their effects using prospective approaches.

Successful pain management commences with pain assessment using validated, age-specific tools appropriate for the patient's condition [24]. The review findings suggest that generic pain assessment tools such as NRS, VAS, and VDS may be appropriate for older adults with burns. The potential of acute confused states, delirium and cognitive impairment occurring among older persons with burns adds an extra layer of complexity in the burn pain management process. It has therefore been recommended that tools such as the Pain Assessment in Advanced Dementia (PAINAD), the Non-communicative Pain Assessment Instrument (NOPPAIN) and the Abbey Pain Scale may be considered [24]. These tools are however yet to be validated among the older adult burn patient population [41]. Within the adult burn patient population, it was reported that pain assessment tools such as the Critical Care Pain Observation Tool (CCPOT) and the Adult Nonverbal Scale (ANVS) are able to discriminate pain intensity but correlate poorly with the patients' self-reports of pain based on the NRS and VAS pain scale scores which is suggestive that not all tools are able to accurately assess a patient's pain [44]. For burned older adults who are unable to self-report their pain, healthcare staff reliance on only objective tools may potentially lead to undertreatment of pain. As noted in this review, pre-existing usage of medications such as beta-blockers and other underlying conditions may even mask the presentation and intensity of pain among burned older adults which can impact objective pain assessment [37]. These findings create a need to ascertain the validity, reliability, feasibility, and outcomes associated with commonly used pain assessment tools in the older adult burn patient population taking into consideration their unique needs. More so, these findings may suggest a need for a multidimensional pain assessment tool specific to the geriatric burn population. As highlighted by Pham, these assertions remain critical issues for consideration/further work [41], particularly considering the increasing ageing population and their increased risk of being involved in burn injuries [45].

Several studies have observed the notable mortality risk [3,4,46-48] and increased mortality rates [49] among older adults with burns. However, the current review did not identify specific pain assessment and interventions at the end of life. Pain management 
at the end-of-life phase in burn care remains blurred. In fact, palliative/end-of-life care guidelines are generally lacking in the burn unit though mortality risk/death may be a reality that may adversely affect the quality of comfort care rendered to older burned adults at the end of life [50]. This is an area that requires input from palliative care services to ensure that pain and other distressing symptoms are satisfactorily managed [50,51].

Further to the above, the review findings highlight the preponderance of opioids (alongside ketamine and midazolam) and acetaminophen in the pharmacological management of procedural and breakthrough pain; used cautiously and titrated incrementally based on individual circumstances and with ongoing monitoring. Interestingly, there were no outcomes noted across the studies included in this review. Though varied pharmacological approaches may exist for younger persons, these cannot be transferred directly to older burned patients without considering important factors such as underlying comorbidities [52]. The finding represents a significant gap as without outcomes, it is difficult, if not impossible to draw strong conclusions. Moreover, the preponderance of pharmacological measures observed in this review suggests that the potential of non-pharmacological approaches for older adults with burns remains largely unexplored. As noted in a previous systematic review, non-pharmacological pain management measures may have an overall positive effect on pain outcomes with no adverse effects in burn patients [25]. Specifically, in children and adolescents, distraction and virtual reality were observed to be effective in reducing pain perception and distress during procedures $[53,54]$. Similarly, non-pharmacological approaches such as virtual reality and hypnosis may help to relieve procedural pain and reduce mental distress among adults with burns [55]. Community-dwelling older persons may also benefit from non-pharmacological pain management strategies such as acupressure, acupuncture, and guided imagery [56]. The utility, suitability, and feasibility of the non-pharmacological approaches need to be explored further alongside the pharmacological approaches and their outcomes ascertained to provide quantitative evidence that can inform the formulation of practice guidelines and protocols.

The review findings further suggest that older burned patients need a holistic approach to pain management which can be attainable by considering a multi-disciplinary approach to care. The burn care team needs further support from other specialists such as geriatricians to plan a holistic pain management plan for an older burned patient. A holistic approach to pain management for the elderly was underscored as essential in literature [52] which requires further work in the geriatric burn patient population. Having such a team may potentially help to overcome barriers that may hinder the optimal management of burn pain and potentially improve patient outcomes [57-59].

\section{Conclusions}

In conclusion, the pain remains an unmet need in the geriatric burn patient population and evidence to underpin practices remain limited. Several gaps exist and the review findings may serve as a guide for further studies in geriatric burn pain management. Strategies remain poorly evaluated and outcomes are largely unexplored. Despite this, the review findings point towards a need for a holistic, multidisciplinary approach to burn pain management. To the author's best knowledge, this is the first review to comprehensively scope and map all that is known regarding geriatric burn pain management. Despite this strength, some limitations are noteworthy. Firstly, most of the evidence sources are review papers with limited primary studies, which may affect the strength of conclusions drawn. Secondly, only studies reported in English were retained in the review which may have led to the exclusion of non-English studies.

Supplementary Materials: The following are available online at https:/ /www.mdpi.com/article/10.3390/ ebj2040014/s1, Table S1: data extraction and synthesis table. 
Author Contributions: J.B. conceptualised the study, reviewed literature, completed the write-up, and approved the final version for submission. The author have read and agreed to the published version of the manuscript.

Funding: This research received no external funding.

Institutional Review Board Statement: Not required for this review.

Informed Consent Statement: Not required for this review.

Data Availability Statement: All data pertaining to this review are available online as a supplementary file.

Acknowledgments: The author wishes to thank the Hong Kong Polytechnic University and his supervisor, Frances Kam Yuet Wong for the space and resources to complete this review.

Conflicts of Interest: The author declares no conflict of interest.

\section{References}

1. Jeschke, M.G.; Peck, M.D. Burn care of the elderly. J. Burn. Care Res. 2017, 38, e625-e628. [CrossRef]

2. Jeschke, M.G.; Phelan, H.A.; Wolf, S.; Romanowski, K.; Rehou, S.; Saetamal, A.; Weber, J.; Schulz, J., III; New, C.; Wiktor, A.; et al. State of the science burn research: Burns in the elderly. J. Burn. Care Res. 2020, 41, 65-83. [CrossRef]

3. Bayuo, J.; Aniteye, P.; Richter, S.; Agbenorku, P. Exploring the Background, Context, and Stressors of Caregiving to Elderly Burned Patients: A Qualitative Inquiry. J. Burn. Care Res. 2021. [CrossRef]

4. Bayuo, J.; Botchway, A.E. Burns among older persons: A narrative review. Burn. Open 2017, 1, 2-8. [CrossRef]

5. Stanojcic, M.; Jeschke, M.G. Burns in the older adult. In Principles and Practice of Geriatric Surgery; Springer: Berlin/Heidelberg, Germany, 2020; pp. 1195-1205.

6. Cunningham, H.B.; Romanowski, K.S.; Phelan, H.A. Geriatric burns. In Handbook of Burns; Springer: Berlin/Heidelberg, Germany, 2020; Volume 1, pp. 401-414.

7. Summer, G.J.; Puntillo, K.A.; Miaskowski, C.; Green, P.G.; Levine, J.D. Burn injury pain: The continuing challenge. J. Pain 2007, 8, 533-548. [CrossRef] [PubMed]

8. Cáceres-Jerez, L.E.; Gomezese-Ribero, O.F.; Reyes-Cárdenas, L.I.; Vera-Campos, J.A.; Guzmán-Rueda, V.A.; Azar-Villalobos, J.P.; Meléndez-Flórez, H.J. Management of acute pain in extensive burn injury: Nonsystematic review of the literature. Rev. Colomb. Anestesiol. 2018, 46, 49-54. [CrossRef]

9. Mahar, P.D.; Wasiak, J.; O'Loughlin, C.J.; Christelis, N.; Arnold, C.A.; Spinks, A.B.; Danilla, S. Frequency and use of pain assessment tools implemented in randomized controlled trials in the adult burns population: A systematic review. Burns 2012, 38, 147-154. [CrossRef] [PubMed]

10. Restrepo, M.S.; Avila, A.J. Considerations for Pain Management in the Burn-Injured Patient, in Burn Care and Treatment; Springer: Berlin/Heidelberg, Germany, 2021; pp. 97-108.

11. Jones, M.R.; Ehrhardt, K.P.; Ripoll, J.G.; Sharma, B.; Padnos, I.W.; Kaye, R.J.; Kaye, A.D. Pain in the elderly. Curr. Pain Headache Rep . 2016, 20, 23. [CrossRef]

12. Gibson, S.J.; Helme, R.D. Age-related differences in pain perception and report. Clin. Geriatr. Med. 2001, 17, 433-456. [CrossRef]

13. Gleason, L.J.; Escue, E.D.; Hogan, T.M. Older adult emergency department pain management strategies. Clin. Geriatr. Med. 2018, 34, 491-504. [CrossRef]

14. Bayuo, J.; Agbenorku, P. Nurses' perceptions and experiences regarding Morphine usage in burn pain management. Burns 2015, 41, 864-871. [CrossRef]

15. Ikeda, H.; Stark, J.; Fischer, H.; Wagner, M.; Drdla, R.; Jäger, T.; Sandkühler, J. Synaptic amplifier of inflammatory pain in the spinal dorsal horn. Science 2006, 312, 1659-1662. [CrossRef]

16. Morgan, M.; Deuis, J.R.; Frøsig-Jørgensen, M.; Lewis, R.J.; Cabot, P.J.; Gray, P.D.; Vetter, I. Burn pain: A systematic and critical review of epidemiology, pathophysiology, and treatment. Pain Med. 2018, 19, 708-734. [CrossRef]

17. Summer, G.J.; Dina, O.A.; Levine, J.D. Enhanced inflammatory hyperalgesia after recovery from burn injury. Burns 2007, 33, 1021-1026. [CrossRef] [PubMed]

18. Van Loey, N.E.E.; Maas, C.J.M.; Faber, A.W.; Taal, L.A. Predictors of chronic posttraumatic stress symptoms following burn injury: Results of a longitudinal study. J. Trauma. Stress: Off. Publ. Int. Soc. Trauma. Stress Stud. 2003, 16, 361-369. [CrossRef] [PubMed]

19. Askay, S.W.; Patterson, D.R. What are the psychiatric sequelae of burn pain? Curr. Pain Headache Rep. 2008, 12, 94-97. [CrossRef] [PubMed]

20. Edwards, R.R.; Magyar-Russell, G.; Thombs, B.; Smith, M.T.; Holavanahalli, R.K.; Patterson, D.R.; Blakeney, P.; Lezotte, D.C.; Haythornthwaite, J.A.; Fauerbach, J.A. Acute pain at discharge from hospitalization is a prospective predictor of long-term suicidal ideation after burn injury. Arch. Phys. Med. Rehabil. 2007, 88, S36-S42. [CrossRef] [PubMed]

21. Yuxiang, L.; Lingjun, Z.; Lu, T.; Mengjie, L.; Xing, M.; Fengping, S.; Jing, C.; Xianli, M.; Jijun, Z. Burn patients' experience of pain management: A qualitative study. Burns 2012, 38, 180-186. [CrossRef] [PubMed]

22. Lynch, E.P.; Lazor, M.A.; Gellis, J.E.; Orav, J.; Goldman, L.; Marcantonio, E.R. The impact of postoperative pain on the development of postoperative delirium. Anesth. Analg. 1998, 86, 781-785. [PubMed] 
23. Spronk, I.; Van Loey, N.E.; Sewalt, C.; Nieboer, D.; Renneberg, B.; Moi, A.L.; Oster, C.; Orwelius, L.; van Baar, M.E.; Polinder, S.; et al. Recovery of health-related quality of life after burn injuries: An individual participant data meta-analysis. PLoS ONE 2020, 15, e0226653. [CrossRef]

24. Bayuo, J.; Munn, Z.; Campbell, J. Assessment and management of burn pain at the Komfo Anokye Teaching Hospital: A best practice implementation project. JBI Evid. Synth. 2017, 15, 2398-2418. [CrossRef]

25. De Jong, A.E.E.; Middelkoop, E.; Faber, A.W.; Van Loey, N.E.E. Non-pharmacological nursing interventions for procedural pain relief in adults with burns: A systematic literature review. Burns 2007, 33, 811-827. [CrossRef] [PubMed]

26. Hoffman, H.G.; Richards, T.L.; Coda, B.; Bills, A.R.; Blough, D.; Richards, A.L.; Sharar, S.R. Modulation of thermal pain-related brain activity with virtual reality: Evidence from fMRI. Neuroreport 2004, 15, 1245-1248. [CrossRef] [PubMed]

27. Arksey, H.; O'Malley, L. Scoping studies: Towards a methodological framework. Int. J. Soc. Res. Methodol. 2005, 8, 19-32. [CrossRef]

28. Levac, D.; Colquhoun, H.; O’Brien, K.K. Scoping studies: Advancing the methodology. Implement. Sci. 2010, 5, 1-9. [CrossRef] [PubMed]

29. Tricco, A.C.; Lillie, E.; Zarin, W.; O’Brien, K.K.; Colquhoun, H.; Levac, D.; Moher, D.; Peters, M.D.; Horsley, T.; Weeks, L.; et al. PRISMA extension for scoping reviews (PRISMA-ScR): Checklist and explanation. Ann. Intern. Med. 2018, 169, 467-473. [CrossRef] [PubMed]

30. Davidge, K.; Fish, J. Older adults and burns. Geriatr. Aging 2008, 11, 270-275.

31. Keck, M.; Lumenta, D.B.; Andel, H.; Kamolz, L.P.; Frey, M. Burn treatment in the elderly. Burns 2009, 35, 1071-1079. [CrossRef]

32. Abu-Sittah, G.; Chahine, F.; Janom, H. Management of burns in the elderly. Ann. Burn. Fire Disasters 2016, $29,249$.

33. Norman, A.T.; Judkins, K.C. Pain in the patient with burns. Contin. Educ. Anaesth. Crit. Care Pain 2004, 4, 57-61. [CrossRef]

34. Connor-Ballard, P.A. Understanding and managing burn pain: Part 2. Am. J. Nurs. 2009, 109, 54-62. [CrossRef]

35. Huang, S.B.; Chang, W.H.; Huang, C.H.; Tsai, C.H. Management of elderly burn patients. Int. J. Gerontol. 2008, 2, 91-97. [CrossRef]

36. Nosanov, L.B.; Brandt, J.L.; Schneider, D.M.; Johnson, L.S. Pain Management in Burn Patients. Curr. Trauma Rep. 2020, 6, 161-173. [CrossRef]

37. Sheridan, R. Burns at the extremes of age. J. Burn. Care Res. 2007, 28, 580-585. [CrossRef]

38. Montgomery, R.K. Pain management in burn injury. Crit. Care Nurs. Clin. 2004, 16, 39-49. [CrossRef] [PubMed]

39. Hutchison, C.; Gayed, R.; Mittal, R. 65 Pain Management Practices in the Elderly Patient with Burn Injury. J. Burn. Care Res. 2021, 42 (Suppl. 1), S46-S47. [CrossRef]

40. Honari, S.; Patterson, D.R.; Gibbons, J.; Martin-Herz, S.P.; Mann, R.; Gibran, N.S.; Heimbach, D.M. Comparison of pain control medication in three age groups of elderly patients. J. Burn. Care Rehabil. 1997, 18, 500-504. [CrossRef] [PubMed]

41. Pham, T.N. Burns in older adults. In Handbook of Burns; Springer: Berlin/Heidelberg, Germany, 2012; pp. $279-289$.

42. Sheaffer, J. Nursing Considerations in the Care of Elderly Burn Patients. In Geriatric Trauma and Acute Care Surgery; Springer: Berlin/Heidelberg, Germany, 2018; pp. 465-474.

43. Faucher, L.; Furukawa, K. Practice guidelines for the management of pain. J. Burn. Care Res. 2006, 27, 659-668. [CrossRef]

44. Wibbenmeyer, L.; Sevier, A.; Liao, J.; Williams, I.; Latenser, B.; Lewis, R.; Kealey, P.; Rosenquist, R. Evaluation of the usefulness of two established pain assessment tools in a burn population. J. Burn. Care Res. 2011, 32, 52-60. [CrossRef]

45. Harvey, L.; Mitchell, R.; Brodaty, H.; Draper, B.; Close, J. Dementia: A risk factor for burns in the elderly. Burns 2016, 42, 282-290. [CrossRef]

46. Duke, J.M.; Boyd, J.H.; Rea, S.; Randall, S.M.; Wood, F.M. Long-term mortality among older adults with burn injury: A population-based study in Australia. Bull. World Health Organ. 2015, 93, 400-406. [CrossRef] [PubMed]

47. Pham, T.N.; Kramer, C.B.; Wang, J.; Rivara, F.P.; Heimbach, D.M.; Gibran, N.S.; Klein, M.B. Epidemiology and outcomes of older adults with burn injury: An analysis of the National Burn Repository. J. Burn. Care Res. 2009, 30, 30-36. [CrossRef]

48. Lundgren, R.S.; Kramer, C.B.; Rivara, F.P.; Wang, J.; Heimbach, D.M.; Gibran, N.S.; Klein, M.B. Influence of comorbidities and age on outcome following burn injury in older adults. J. Burn. Care Res. 2009, 30, 307-314. [CrossRef] [PubMed]

49. Harats, M.; Ofir, H.; Segalovich, M.; Visentin, D.; Givon, A.; Peleg, K.; Kornhaber, R.; Cleary, M.; Haik, J. Trends and risk factors for mortality in elderly burns patients: A retrospective review. Burns 2019, 45, 1342-1349. [CrossRef] [PubMed]

50. Bayuo, J.; Bristowe, K.; Harding, R.; Agyei, F.B.; Agbeko, A.E.; Agbenorku, P.; Baffour, P.K.; Allotey, G. Hoyte-Williams, P.E., The role of palliative care in burns: A scoping review. J. Pain Symptom Manag. 2020, 59, 1089-1108. [CrossRef] [PubMed]

51. Ray, D.E.; Karlekar, M.B.; Crouse, D.L.; Campbell, M.; Curtis, J.R.; Edwards, J.; Lustbader, D.R.; Mosenthal, A.C.; Mulkerin, C.; Puntillo, K.A.; et al. Care of the critically ill burn patient. An overview from the perspective of optimizing palliative care. Ann. Am. Thorac. Soc. 2017, 14, 1094-1102. [CrossRef] [PubMed]

52. McCleane, G. Pharmacological pain management in the elderly patient. Clin. Interv. Aging 2007, 2, 637. [CrossRef] [PubMed]

53. Hadoush, H.; Alruz, S.; Kassab, M.; Roy, A.N. Non-pharmacological Management of Burn-related Pain and Distress in Children: A Systematic Review and Meta-Analysis Study. Syst. Rev. Pharm. 2021, 12, 423-438.

54. Lauwens, Y.; Rafaatpoor, F.; Corbeel, K.; Broekmans, S.; Toelen, J.; Allegaert, K. Immersive virtual reality as analgesia during dressing changes of hospitalized children and adolescents with burns: A systematic review with meta-analysis. Children 2020, 7, 194. [CrossRef]

55. Scheffler, M.; Koranyi, S.; Meissner, W.; Strauss, B.; Rosendahl, J. Efficacy of non-pharmacological interventions for procedural pain relief in adults undergoing burn wound care: A systematic review and meta-analysis of randomized controlled trials. Burns 2018, 44, 1709-1720. [CrossRef] 
56. Tang, S.K.; Tse, M.M.Y.; Leung, S.F.; Fotis, T. The effectiveness, suitability, and sustainability of non-pharmacological methods of managing pain in community-dwelling older adults: A systematic review. BMC Public Health 2019, 19, 1488. [CrossRef]

57. Kaye, A.D.; Baluch, A.; Scott, J.T. Pain management in the elderly population: A review. Ochsner, J. 2010, 10, $179-187$.

58. Kaye, A.D.; Baluch, A.R.; Kaye, R.J.; Niaz, R.S.; Kaye, A.J.; Liu, H.; Fox, C.J. Geriatric pain management, pharmacological and nonpharmacological considerations. Psychol. Neurosci. 2014, 7, 15-26. [CrossRef]

59. Nguyen, A.T.; Dang, A.K.; Nguyen, H.T.T.; Nguyen, T.X.; Nguyen, T.N.; Nguyen, T.T.H.; Pham, T.; Nguyen, A.L.; Nguyen, T.T.N.; Thi, H.N.; et al. Assessing Knowledge and Attitudes Regarding Pain Management Among Nurses Working in a Geriatric Hospital in Vietnam. J. Multidiscip. Healthc. 2021, 14, 799. [CrossRef] 